\title{
Diálogos Brasil-México : a estreitar laços
}

\section{Wilson Trajano Filho e Carla Costa Teixeira}

\section{(2) OpenEdition}

Journals

Edição electrónica

URL: http://journals.openedition.org/aa/1327

DOI: $10.4000 /$ aa. 1327

ISSN: 2357-738X

\section{Editora}

Programa de Pós-Graduação em Antropologia Social (UnB)

\section{Edição impressa}

Data de publição: 1 julho 2015

Paginação: 9-22

ISSN: 0102-4302

\section{Refêrencia eletrónica}

Wilson Trajano Filho e Carla Costa Teixeira, «Diálogos Brasil-México : a estreitar laços», Anuário

Antropológico [Online], v.40 n.1 | 2015, posto online no dia 01 junho 2018, consultado o 28 abril 2021. URL: http://journals.openedition.org/aa/1327 ; DOI: https://doi.org/10.4000/aa.1327

\section{(c) (i) () $\Theta$}

Anuário Antropológico is licensed under a Creative Commons Atribuição-Uso Não-Comercial-Proibição de realização de Obras Derivadas 4.0 International. 


\title{
Diálogos Brasil-México: a estreitar laços
}

\author{
Wilson Trajano Filho
}

$\mathrm{UnB}$

Carla Costa Teixeira

$\mathrm{UnB}$

Em uma conferência proferida em 1997, sintomaticamente, no 49 Congresso Internacional de Americanistas, realizado em Quito, Equador, o decano da antropologia brasileira, professor Roberto Cardoso de Oliveira, chamava a atenção para o fato de que as antropologias das periferias estavam interessadas basicamente no que se passava nos seus próprios territórios ou regióes, e os seus praticantes pouco conheciam o que se produzia nas outras comunidades antropológicas periféricas, dedicando-se prioritariamente ao diálogo (fantasioso no mais das vezes, diríamos nós) com a produção realizada nos países do centro (Cardoso de Oliveira, 2006). Nessa mesma ocasião, nosso decano propunha que a concentração das pesquisas nos próprios territórios nacionais dos antropólogos seria um dos indicadores úteis para o exame comparativo das antropologias que fazemos nas periferias do sistema mundial.

Alguns anos mais tarde, um dos autores do presente texto, comungando a mesma linha de pensamento, afirmava que a produção antropológica brasileira se caracterizava pela dominância dos temas nacionais e que eram poucos os antropólogos a se aventurarem em pesquisas fora de nossas fronteiras, mas apontava para tênues sinais de mudança (Trajano Filho \& Martins, 2004). Em 2014, esse mesmo autor ressaltava que havia nos departamentos de antropologia das universidades brasileiras cerca de 30 pesquisadores doutores com experiência de pesquisa em contextos africanos (Trajano Filho, 2014). Essas mesmas instituiçóes abrigam atualmente mais de meia centena de antropólogos com interesse de pesquisa em outras partes do mundo. Passados mais de quinze anos da conferência do professor Roberto Cardoso de Oliveira, observa-se uma gradual mas evidente tendência ao alargamento de horizontes de pesquisa na antropologia feita no Brasil.

Apesar da crescente internacionalização da antropologia brasileira, permanece entre nós o sentimento difuso de que conhecemos pouco o que se faz na antropologia da América Latina. Esse sentimento é ainda mais dolorido e provocador quando se trata do México, por se tratar de uma comunidade antropológica muito grande, muito qualificada e, de certo modo, semelhante à brasileira, no que diz respeito 
ao seu relacionamento com o Estado nacional. Sabemos hoje que esse sentimento é recíproco, havendo entre os antropólogos mexicanos um genuíno interesse em conhecer e estreitar os laços institucionais e o diálogo intelectual com os colegas brasileiros.

As trocas intelectuais entre cientistas sociais dos dois países datam pelo menos do início dos anos de 1960, quando Rodolfo Stavenhagen passou uma temporada no Centro Latino-Americano de Ciências Sociais, no Rio de Janeiro, na época dirigido por Manuel Diegues Jr. Data desse período o encontro do sociólogo mexicano com Roberto Cardoso de Oliveira, então baseado no Museu Nacional, da Universidade Federal do Rio de Janeiro. Desde então, foram muitos os encontros envolvendo antropólogos brasileiros, mexicanos e latino-americanos, como a II Reunión para la Integración de la Enseñaza en las Investigaciones Antropológicas e o $6^{\circ}$ Congresso Indigenista Interamericano, realizados no México, em 1968, o $8^{\circ}$ Congresso Indigenista Interamericano, sediado em Brasília, em 1972, e o Seminário Latino-Americano de Antropologia, ocorrido nessa mesma cidade em 1987. Mas de algum modo a sede por um diálogo mais intenso e regular fez com que, em 2012, um grupo de antropólogos dos dois países engendrasse esforços para promover reunióes bienais regulares de modo a ultrapassar esse fosso e intensificar as trocas intelectuais entre as duas comunidades. Foi assim que surgiram os Encontros de Antropólogos Mexicanos e Brasileiros (EMBRA).

As comunidades antropológicas de Brasil e México, como já havia sido ressaltado em 2012, quando da publicação das conferências do I EMBRA, guardam afinidades históricas e de relevância em seus respectivos campos científicos nacionais e latino-americano, não apenas pela qualidade de sua produção acadêmica, mas também devido às fortes presenças que atualizam, embora de forma distinta, nas esferas públicas de seus países. Tais afinidades têm se frutificado com a publicação de textos e livros clássicos da antropologia brasileira na Coleção Clásicos y Contemporâneos en Antropología (CIESAS, UIA, UAM-1), que, por meio do acesso gratuito a autores brasileiros em espanhol, permite intensificar a permeabilidade entre essas tradiçóes disciplinares. ${ }^{1} \mathrm{Com}$ a mesma orientação, a articulação entre CIESAS, Embaixada do Brasil no México e Editora da UnB permitiu lançar a Biblioteca Mexicano-Brasileira de Antropología y Ciencias Sociales. ${ }^{2}$ No Brasil, coletâneas organizadas de forma conjunta por antropólogos brasileiros e mexicanos podem ser encontradas no acervo de publicaçóes da Associação Brasileira de Antropologia, ${ }^{3}$ bem como artigos de antropólogos mexicanos podem ser lidos em vários periódicos brasileiros de reconhecida relevância ${ }^{4}$ e vice-versa. ${ }^{5}$ 


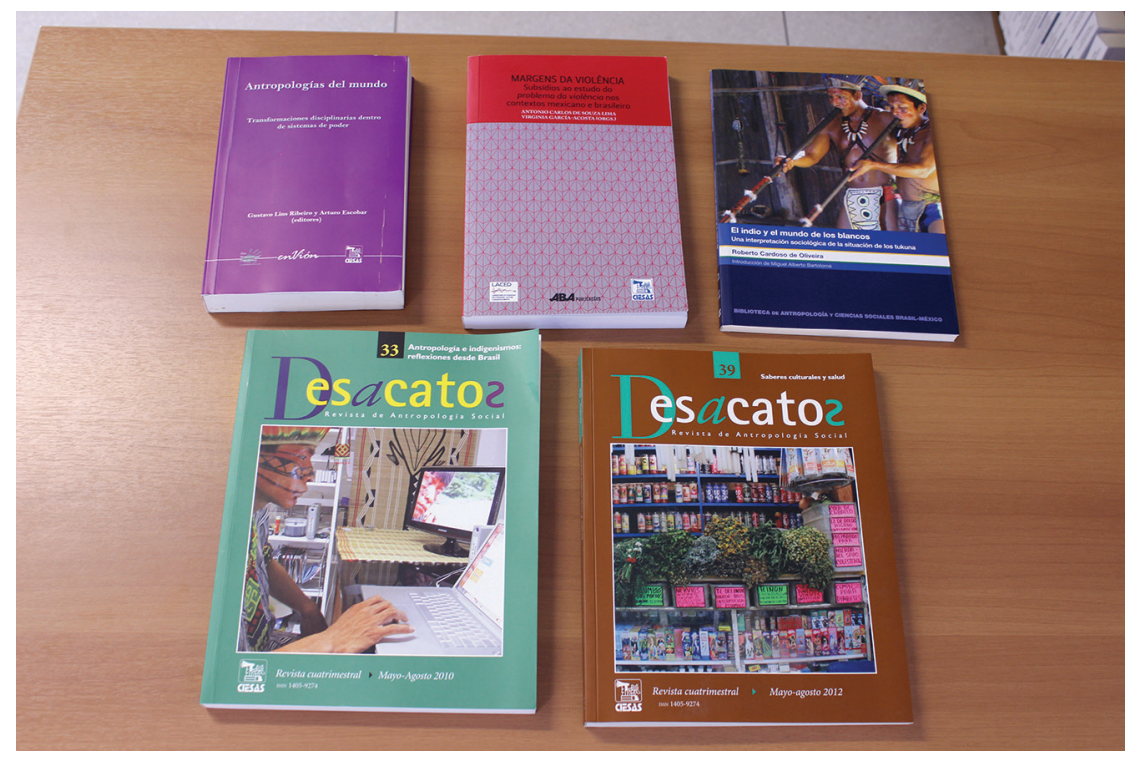

Imagem 1: Publicaçóes oriundas do diálogo entre as comunidades antropológicas de Brasil e México

Se a leitura mútua de escritos antropológicos mexicanos e brasileiros é fundamental para a construção de um campo comum de preocupaçóes e reflexôes e para a proposição de novas perspectivas comparativas, há que destacar a relevância da troca de experiências face a face na sua consolidação. Tais experiências, tanto em eventos da Associação Latino-Americana de Antropologia, de Antropologia do Mercosul, e, mais recentemente, nos Encontros (bienais) entre Antropólogos Mexicanos e Brasileiros quanto na permuta de professores em estadias prolongadas (a ministrarem palestras, minicursos e cursos regulares de pós-graduação) e nos intercâmbios de estudantes de pós-graduação, são centrais ao adensamento das relaçóes sociais tão caras à longevidade das proximidades intelectuais. Afinal, são essas situações que tornam possível a articulação de redes de investigadores que, mais ou menos institucionalizadas, geram convites, publicaçóes e novos eventos.

Foi no espírito de continuidade e renovação dessas iniciativas institucionais que o Departamento e o Programa de Pós-Graduação em Antropologia da Universidade de Brasília (DAN e PPGAS/UnB) organizaram o II Encontro entre Antropólogos Mexicanos e Brasileiros (II EMBRA), de 3 a 6 de novembro de 2013, em articulação com o Centro de Investigaciones y Estudios Superiores en Antropología Social (CIESAS). Se o I Encontro, realizado dois anos antes na Cidade do México, focalizou a identificação e discussão de temas de interesse comum, em Brasília, a segunda versão do Encontro contribuiu para que pesquisadores antropólogos de ambos os países delineassem uma agenda de trabalho conjunta, 
com vistas a permitir articulaçôes entre instituiçóes, bem como constituíssem redes de investigadores binacionais a fim de desenvolver atividades e pautas de pesquisa continuadas.

Realizado no Memorial Darcy Ribeiro, o II EMBRA congregou 158 antropólogos de ambos os países, entre os quais 93 professores e pesquisadores, 40 pós-graduandos e 25 graduandos. Além da diversidade de momento de formação profissional, é preciso destacar a diversificada pertença institucional dos participantes. Afora a presença de antropólogos das instituiçóes organizadoras, PPGAS/UnB e CIESAS, muitos colegas vieram de outras instituiçóes de ensino e pesquisa. Se considerarmos a origem institucional dos brasileiros, por exemplo, cerca de 60\% dos participantes eram da Universidade de São Paulo, da Universidade Estadual de Campinas, da Universidade Federal de São Carlos, da Universidade Federal do Rio Grande do Sul, da Universidade Federal do Rio de Janeiro, da Universidade Federal Fluminense, da Universidade Federal de Santa Catarina, da Universidade Federal do Amazonas, da Fundação Instituto Oswaldo Cruz, da Universidade Federal do Pará, da Universidade Federal do Rio Grande do Norte e da Universidade Federal do Paraná, entre outras.

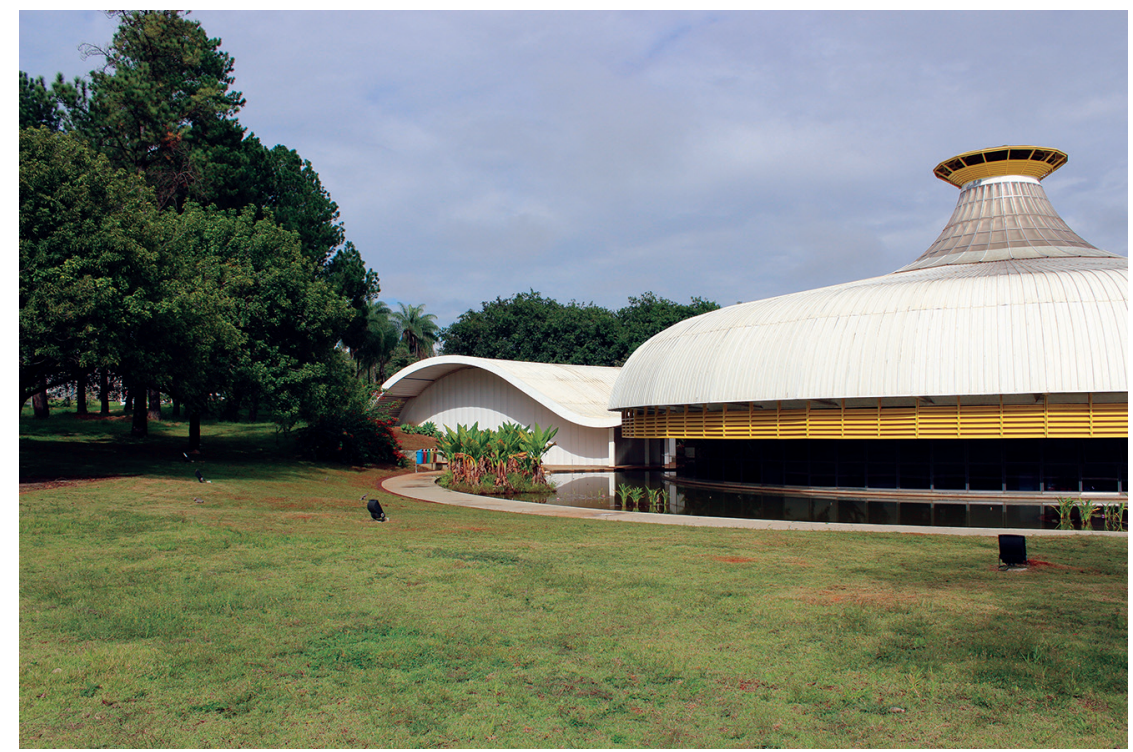

Imagem 2: Memorial Darcy Ribeiro (UnB)

Visto desse ângulo, o II EMBRA fez mais do que aprofundar as relações entre o PPGAS/UnB e o CIESAS — relaçóes estas que, desde 2007, adquiriram a forma de um convênio institucional que prevê projetos institucionais de pesquisa; intercâmbio de professores, pesquisadores e estudantes de pós-graduação; troca de informação, documentação e publicaçôes científicas; e encontros de estudo, Anuário Antropológico/2014, Brasília, UnB, 2015, v. 40, n. 1: 9-22 
reuniôes, cursos, seminários, colóquios e simpósios. Os quatro dias de evento propiciaram a ampliação da rede institucional de diálogo entre as comunidades antropológicas brasileira e mexicana horizontal e verticalmente, ou seja, a sua expansão para várias das mais de vinte pós-graduaçôes em antropologia social existentes no Brasil e, também, a articulação entre geraçóes de antropólogos seniores e juniores - condição necessária à reprodução dessas redes além de seus articuladores originários. Se em sua versão anterior o EMBRA já trazia a marca da diversidade de instituições brasileiras participantes, sua realização em Brasília possibilitou amplificá-la.

Ao lançar um olhar transversal sobre as temáticas abordadas nas duas edições do Encontro, em 2011 e 2013, pode-se vislumbrar um processo de delineamento de áreas de interesse compartilhadas. Tal processo parece apontar para a combinação de áreas já consolidadas no campo da antropologia — em diferentes contextos nacionais e próprias às histórias da disciplina no Brasil e no México - , com recortes de problemas que têm desafiado mais recentemente a antropologia da perspectiva dos mexicanos e brasileiros.

É interessante, antes de prosseguir no aprofundamento dessa dimensão do evento, apresentar a forma como tem se dado a definição do temário a compor sua agenda de debates: a comissão organizadora da instituição sede constrói uma proposta inicial, que servirá de base para a comissão da instituição coorganizadora (DAN e PPGAS/UnB em 2011; CIESAS em 2013) propor alteraçóes e mapear antropólogos de seu país que possam participar do evento em cada mesa/painel ou grupo de trabalho, que vem a ser definido após um vai e vem de ajustes entre as comissões. Tal dinâmica tem permitido, além da alternância das responsabilidades que qualificam a organização de um encontro binacional, a produção de certo modo de fazer institucional que exercita o respeito às dinâmicas próprias a ambas as comunidades nacionais, ao mesmo tempo em que atualiza um desenho náo existente anteriormente - é um evento multitemático que não tem se articulado, como em geral se observa, por iniciativa das associações científicas antropológicas de nenhum dos países envolvidos. Por meio dessa experiência de produção institucional, antropólogos mexicanos e brasileiros vêm a construir mais do que uma agenda comum de pesquisas: compartilham procedimentos organizacionais próprios aos seus contextos e, assim, apreendem as especificidades dessa dimensão tâo importante da produção intelectual, que, frequentemente oculta, é condição de sua realização. 


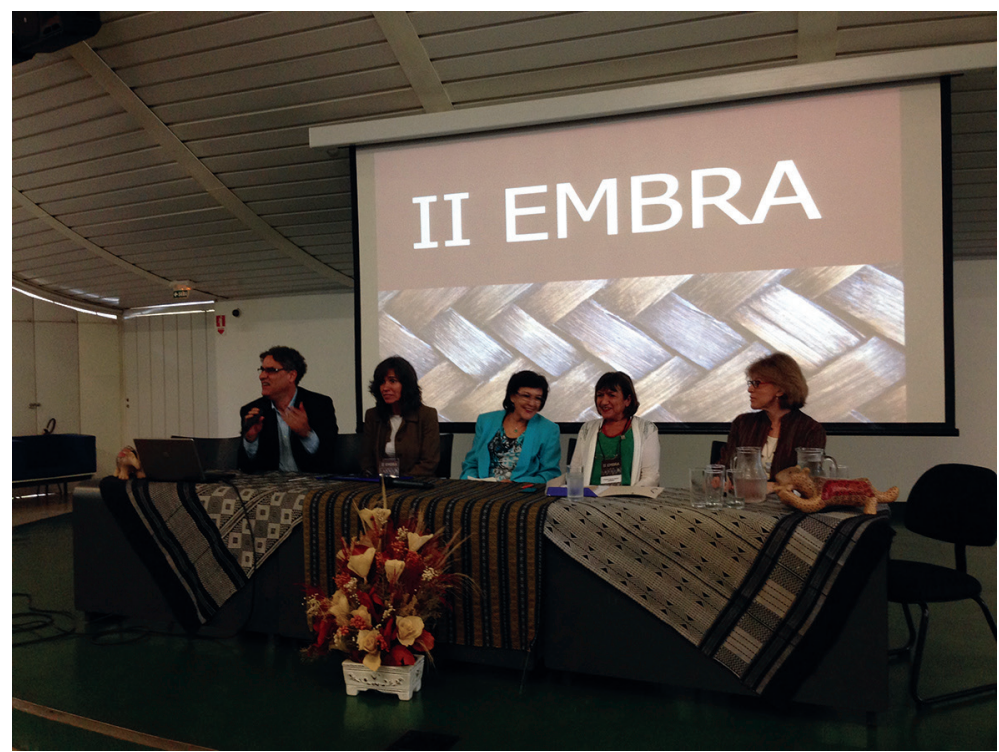

Imagem 3: Mesa de Encerramento do II EMBRA

Com isso em mente, pode-se agora retomar o olhar transversal anunciado anteriormente. $\mathrm{Na}$ consulta às programaçôes, verifica-se que algumas temáticas se mantiveram nas duas edições do Encontro, outras foram especificadas, desdobradas ou reorientadas, e novas foram propostas. Ao buscar traçar esses fios de continuidade e renovação com os da consolidação e desafio nos temas antropológicos abordados em ambos os eventos, destacam-se sem qualquer alteração nominal: Globalização e Migrações; Formação da Nação e Relação com o Estado; e Gênero, Corpo e Sexualidade. Já outros temas se mantiveram com reorientação de foco: direitos humanos; ética em pesquisa; políticas públicas; antropologia médica/da saúde; educação; e antropologias nacionais. Entre as propostas ou abordagens novas para temas clássicos da antropologia, encontramse: (um novo olhar sobre) economia; (transnacionalidade do) religioso; riscos e desastres; e recursos naturais, ecologia e sociedade. $\mathrm{O}$ que assume relevância inquestionável na pauta de discussão, contudo, são as reflexôes em torno da etnicidade, diversidade cultural e formação do Estado e da nação. Essa relevância é claramente tributária da importância analítica e política dos estudos sobre o "ser indígena” em ambos os contextos nacionais: na teoria das relaçóes interétnicas, nas elaboraçóes renovadas da categoria de indigenismo, no enfrentamento dos desafios de pensar a cidadania indígena (mas não apenas) e as concepçóes de igualdade e diferença, bem como na evocação de Guillermo Bonfil Batalla e Roberto Cardoso de Oliveira como fundadores do diálogo ao qual se dava continuidade por meio do I e do II EMBRAs. 
A organização formal se manteve a mesma nos dois encontros, que tiveram a duração de quatro dias. Pelas manhãs, ocorreram as mesas-redondas, compostas por dois pesquisadores de cada país, e às tardes, os grupos de trabalho, formados por três ou quatro investigadores de cada país e um comentador responsável pela síntese das ideias apresentadas. Nos dois primeiros dias, as atividades foram iniciadas com conferências magistrais proferidas por um representante da cada comunidade antropológica. O professor Luís Roberto Cardoso de Oliveira (PPGAS/UnB) apresentou o texto "Cidadania, direitos e diversidade", e o professor Guillermo de la Peña (CIESAS-Occidente), a conferência "Ciudades, diversidades y ciudadanias en la antropología mexicana”. Essas conferências, agora publicadas no Anuário Antropológico, representam o que há de melhor no pensamento desses renomados e respeitados pesquisadores e, dessa maneira, são bastante representativas da qualidade da pesquisa feita na antropologia dos dois países.

Se ficarmos restritos aos títulos, certamente seremos iludidos por uma aparente diversidade temática das conferências. No entanto, um exame mais cuidadoso dos textos vai nos revelar que, apesar de não ter havido concertaçáo entre os dois conferencistas, as problemáticas da cidadania e dos direitos (de minorias e movimentos sociais associados à diversidade étnico-cultural) e das diferentes concepçóes da igualdade e da diferença no mundo cívico adquirem uma centralidade que decorre, sem dúvida, da importância política e teórica que a temática indígena tem tido nessas duas comunidades antropológicas. Isso se dá mesmo quando tal temática não se conforma como objeto de interesse primário dos conferencistas, como é o caso.

A conferência de Luís Roberto Cardoso de Oliveira é um desenvolvimento de suas investigaçóes na área da antropologia jurídica (1996, 2011). Nesse texto, o autor examina as complexas relaçôes entre as noçóes de cidadania e igualdade de direitos. $\mathrm{O}$ texto tem como interesse primeiro o exame de uma tensão entre duas concepções de igualdade em competição no mundo cívico brasileiro, que, conforme aponta o autor, padece da boa conformação para definir os limites e as zonas de atuação de cada uma dessas concepçóes. Guiado pela perspectiva comparativa que habita o cerne da boa prática antropológica, o autor examina ainda os modos de ver e vivenciar a igualdade de direitos nos Estados Unidos e na França, isto é, como uma expressão de respeito à dignidade de todos os cidadáos. $\mathrm{O}$ caso brasileiro tem para Cardoso de Oliveira uma singularidade paradoxal, já que há nessa sociedade circunstâncias em que a igualdade é vivida como valor da esfera pública e em que o tratamento igualitário é esperado; nessa mesma sociedade, no entanto, não são raras as ocasióes em que o espaço público 
é marcado por práticas de discriminação cívica, com os atores acionando direitos e privilégios que implicam tratamento diferenciado segundo o status e a condição social.

Praticante de uma antropologia socialmente interessada, Cardoso de Oliveira quer compreender como uma noção de igualdade que implica direitos diferenciados pode não ser ofensiva à dignidade dos cidadãos, como acontece na maioria dos casos que ele analisa. Para tal, o autor aciona mais uma vez seu olhar comparativo, dirigindo-o ao caso do Quebec e suas demandas de reconhecimento como uma sociedade distinta do restante do Canadá. Cardoso de Oliveira mostra que, longe de ser uma arbitrariedade, a demanda quebequense pela quebra do tratamento uniforme e pelo reconhecimento de uma identidade distinta é, no fundo, a condição para a valorização da identidade quebequense e para o exercício de direitos igualitários no mundo cívico. Para os moradores do Quebec, a percepção do tratamento uniforme e a falta de atenção à peculiaridade dessa província são percebidas como um ato de inferiorização ofensivo à dignidade dos cidadáos. Assim, de modo diverso do tratamento diferenciado, que no Brasil discrimina direitos de acordo com a condição social e o status do cidadão, a demanda pelo reconhecimento do Quebec como uma sociedade distinta é motivada pelo desejo de gozar, no plano da cidadania, o mesmo status e a mesma dignidade.

Uma situação semelhante à quebequense é encontrada pelo autor no caso das demandas por direitos diferenciados de indígenas, quilombolas e populaçóes tradicionais brasileiras. Contudo, as minorias étnico-culturais no Brasil se veem perante um Estado e uma sociedade com uma grande dificuldade em respeitar esses direitos e mesmo em tratar com a devida consideração as demandas de tratamento diferenciado. Uma exclusão discursiva por parte do Estado e da sociedade mais ampla atua de modo a negar ou reduzir a dignidade das minorias, muitas vezes não as considerando interlocutores plenos.

O texto "Ciudades, diversidades y ciudadanias en la antropología mexicana", de Guillermo de la Peña, vem trazer para o público de antropólogos brasileiros um quadro bastante instigante e de certa maneira inusitado da antropologia feita no México nos últimos 50 anos. De la Peña inicia seu texto referindo-se ao estereótipo que caracterizaria a antropologia mexicana do século XX como a disciplina voltada para o estudo das comunidades indígenas, tratadas como localidades de pequeno porte, corporadas e fechadas em si mesmas. O autor ressalta que, de fato, o mundo indígena rural e suas comunidades tradicionais foi a grande estrela da antropologia feita até cerca de 1960 sobre o México, por mexicanos ou não. Mas mesmo os estudos hoje clássicos de Wolf (1955), Redfield (1956) e Caso (1948) 
apontavam que não se podia compreender o universo tradicional das populaçóes indígenas sem levar em conta a sua relação ambivalente com o mundo urbano.

Éao universo das cidades que a conferência de de la Peña se volta. Seu texto passa em revista as investigaçóes antropológicas sobre as cidades realizadas nos últimos 50 anos no México. De saída, o autor mostra que essas pesquisas questionaram dicotomias duradouras no pensamento social mexicano, como as do rural/ urbano, tradicional/moderno, indígena/nacional e local/global. De maneira muito curiosa, porém, a antropologia urbana feita no México não abandonou o interesse pelo mundo indígena; pelo contrário, o renovou. $\mathrm{O}$ trabalho antropológico nas cidades aporta novos conhecimentos sobre os indígenas do país - tanto os que passaram a viver nas cidades como os que estão em fluxo e os que permanecem nas comunidades rurais indígenas —, bem como lançar uma nova luz sobre a complexidade sociocultural da nação mexicana.

A história do México nos revela que, depois da violência da revolução, o governo deu início a um programa de reforma agrária de grande escala que já havia repartido, por volta de 1960, uma enormidade de terra entre a população rural. Essa reforma, iniciada depois de 1921, com outras políticas públicas, consolidou por algum tempo um campesinato relativamente viável no país, apesar das relaçôes assimétricas entre a economia camponesa e o agronegócio capitalista. Porém, a expansão do capitalismo industrial na segunda metade do século XX acarretou uma crise sem precedentes no mundo rural e um processo intenso de urbanizaçáo do país. A emergência das cidades como tema caro à antropologia mexicana se deve, portanto, a mudanças sociais profundas nesse período que vieram a configurar as cidades mexicanas como cenário muito importante para a vida social. Em 1960, cerca de metade dos 35 milhóes de mexicanos viviam em pequenas localidades. Em 2010, somente $20 \%$ da população de 110 milhôes viviam em comunidades desse tipo.

Nos anos de 1960, marco do início do processo de urbanização mexicano, os antropólogos daquele país não tinham um instrumental teórico e metodológico para fazer pesquisa nas cidades sem que se abandonassem a visada etnográfica e o interesse simultâneo, que tanto caracteriza a disciplina antropologia, na cultura e na organizaçáo social. A rica conferência de Guillermo de la Peńa vem nos mostrar que esse desafio foi enfrentado pelos colegas mexicanos, que, com êxito, responderam aos problemas de escala que assolam a investigação, em sociedades complexas, das ambíguas relaçóes entre projetos individuais e demandas coletivas em contextos marcados pela fluidez das fronteiras e das relaçóes entre minorias étnicas e Estado nacional nos processos de demandas de direitos e reconhecimento. 
$\mathrm{Na}$ década seguinte, ocorreu uma inflexão na antropologia urbana mexicana, que abandonou as tipologias das cidades estabelecidas por Redfield e a consequente forma de abordá-las como uma totalidade observada do exterior. A intenção a partir de entáo foi compreender etnograficamente as cidades, com foco na perspectiva dos grupos que as formavam. Entraram em cena nos estudos urbanos ideias de rede e de marginalidade, sobretudo as redes e a estratégia de sobrevivência dos pobres urbanos, majoritariamente indígenas que deixaram as suas comunidades rurais tradicionais. Os estudos sobre a pobreza trouxeram um quadro do mundo urbano mexicano como um espaço de reorganizaçáo comunal, de reprodução da desigualdade e de reforço do controle social por meio das complexas relaçôes de patronagem exercidas por caciques urbanos. Esses estudos sobre marginalidade e informalidade enfrentavam o problema da escala etnográfica no complexo e vasto meio urbano, que escapa à observação direta do antropólogo com base na ideia de rede social traçada desde uma pessoa ou um grupo familiar investigado. Foi com essa solução metodológica que se ampliou o leque das investigaçóes urbanas, que passaram a cobrir os espaços de proletarização da força de trabalho nos centros urbanos (industriais, mineiros, turísticos etc.), os movimentos sociais que se tornavam os novos sujeitos coletivos urbanos e os fluxos e circuitos migratórios que conectavam e colocavam em rede as cidades mexicanas entre si e com as zonas rurais e urbanas nos Estados Unidos, para onde convergia grande parcela dos imigrantes mexicanos.

Em todos esses estudos (muitos deles enfocando um espaço urbano claramente transnacional), sobressaía a importância dos vínculos de natureza corporada na vida das pessoas no meio urbano. De modo muito interessante, eles desvelaram a vasta gama de respostas que os migrantes indígenas do campo para as cidades davam ao dilema da manutenção ou do rompimento dos laços comunitários e da identidade étnica no novo ambiente da cidade. Com a crise da economia camponesa, quando se migrou de modo permanente para as cidades, as estratégias de sobrevivência muitas vezes levaram os migrantes a formar verdadeiros vilarejos urbanos, enclaves étnicos nas cidades, onde se reelaborava parcialmente o mundo social e cultural das comunidades corporadas rurais, no qual a ajuda mútua e outras estratégias tradicionais ressignificadas davam o tom da vida urbana.

Surgiu então uma pletora de movimentos sociais com demandas indígenas por direitos específicos a partir de 1970. Guillermo de la Peña mostra que, se as reformas constitucionais de 1992 e 2001 reconheceram alguns desses direitos, bem como algum grau de autonomia cultural, política e jurídica às comunidades indígenas, os indígenas citadinos abordados nas investigaçóes da antropologia urbana não foram de modo algum atendidos em suas demandas. Assim, um Anuário Antropológico/2014, Brasília, UnB, 2015, v. 40, n. 1: 9-22 
dos grandes dilemas da antropologia urbana atualmente feita no México tem a ver com a urgente questão de compreender as dificuldades encontradas pelos indígenas das cidades para exercer seus direitos culturais e políticos. Isso se faz parcialmente com uma documentação etnográfica rigorosa dos inúmeros casos de discriminação negativa vivida pelos indígenas das cidades e de violaçóes ao direito à diversidade. E se faz, também, com o registro cuidadoso das formas de resistência oferecida pelos indígenas à brutal hostilidade que nega ou retira os direitos de cidadania diferenciada aos indígenas que vivem nas cidades.

Como se deve ter notado da breve exposição dessas conferências, há uma convergência entre os dois autores no exame da temática das demandas por direitos e na detecção das formas de discriminação negativa associadas à negação do reconhecimento dos direitos específicos de minorias étnico-culturais. Isso não nos parece produto do acaso ou da idiossincrasia das escolhas dos pesquisadores. A centralidade da questão indígena nas comunidades antropológicas mexicana e brasileira, o engajamento intelectual e político dos antropólogos nas lutas das minorias étnico-culturais e a postura crítica que eles têm das perspectivas excludentes que, de algum modo, prevalecem nas culturas políticas brasileira e mexicana são fatores que devem ser levados em conta na compreensão dessa convergência.

Os participantes do II EMBRA puderam assistir a duas instigantes conferências que provocam o espírito em busca de novos caminhos analíticos e teóricos. Por exemplo, a nosso ver o diálogo Brasil-México consolidado nesse segundo encontro de antropólogos pode instigar Cardoso de Oliveira (ou investigadores de seu grupo de pesquisa) a alagar seu interesse comparativo e elaborar novas comparaçóes que suplementem as tradicionais com o mundo anglo-saxáo e francês. Comparar noçôes de igualdade e cidadania e de tratamento diferenciado entre México e Brasil pode trazer à baila novas luzes e problemas.

A antropologia urbana mexicana revista por Guillermo de la Peña pode servir de espelho para realçar facetas da antropologia urbana feita no Brasil. Igualmente, esta última pode, pela comparaçáo, aportar um novo entendimento aos estudos dos antropólogos mexicanos sobre as cidades passados em revista numa das conferências magistrais do II EMBRA. Pelo espelhamento, notamos que a antropologia urbana feita no Brasil não se destacou pela centralidade dada aos fluxos migratórios indígenas para as cidades. Por exemplo, não abundam estudos como o de Nakashima e Albuquerque (2011) sobre os Pankararu em São Paulo. Igualmente pela reflexão espelhada, acreditamos que estudos urbanos realizados no México não deram destaque à questão do estigma, dos estilos de vida, dos grupos marginalizados e dos projetos individuais que tanto caracterizaram a 
antropologia urbana liderada por Gilberto Velho (1973, 1981, 1994) no Museu Nacional. A marginalidade mexicana parece ser a do mercado e não a da cultura. As razóes desses caminhos diferenciados escapam à nossa competência, mas podem bem ser examinadas pelos especialistas dos dois países interessados numa perspectiva comparada que proponha outros diálogos entre essas duas vibrantes e maduras tradições do fazer antropológico.

Wilson Trajano Filho é Professor do Departamento de Antropologia da Universidade de Brasília e pesquisador associado ao Max Planck Institute for Social Anthropology em Halle-Saale (Alemanha). Antropologia da África e do colonialismo, processos de crioulização e cultura popular são suas principais áreas de pesquisa. Contato: trajano@unb.br

Carla Costa Teixeira é professora o Depto. de Antropologia da Universidade de Brasília, no qual é coordenadora do Laboratório de Antropologia, Saúde e Saneamento (LASS); é pesquisadora do CNPq e tem se dedicado principalmente ao estudo dos seguintes temas: etnografia da vida política, políticas públicas de saúde indígena e relaçóes entre saúde e saneamento. 


\section{Notas}

1. Disponível em: http://www.ciesas.edu.mx/Publicaciones/Clasicos/Index.html. Acesso em: 03/05/2015.

2. Disponível em: http://www.embajadadebrasilcentrocultural.org.mx/biblioteca. html. Acesso em: 03/05/2015.

3. Disponível em: http://www.portal.abant.org.br/index.php/bibliotecas/livros. Acesso em: 03/05/2015.

4. Disponível em: http://www-periodicos-capes-gov-br.ez54.periodicos.capes. gov.br/index.php?option=com_phome; http://www.openedition.org/12177; e http:// aa.revues.org/. Acesso em: 03/05/2015.

5. Disponível em: http://www.scielo.org.mx/scielo.php?script=sci_ alphabetic\&lng=es\&nrm=iso e http://desacatos.ciesas.edu.mx/index.php/Desacatos. Acesso em: 03/05/2015.

\section{Referências bibliográficas}

Cardoso de Oliveira, Luís Roberto. 1996. "Entre o justo e o solidário: os dilemas dos direitos de cidadania no Brasil e nos EUA". Revista Brasileira de Ciências Sociais, 11(31):67-81.

2011. Direito legal e insulto moral: dilemas da cidadania no Brasil, Quebec e EUA. 2. ed. Rio de Janeiro: Garamond.

Cardoso de Oliveira, Roberto. 2006. O trabalho do antropólogo. 3. ed. Brasília: Paralelo 15.

Caso, Alfonso. 1948. "Definición del indio y lo indio”. América Indígena, 8:275-280.

Nakashima, Edson Y. \& Albuquerque. M. A. 2011. "A cultura política da visibilidade: os Pankararu na cidade de São Paulo.” Estudos Históricos, 47:182-201.

Redfield, Robert. 1956. The Little Community/Peasant Society and Culture. Chicago: The University of Chicago Press.

Trajano Filho, Wilson. 2014. "Estudos africanos e as experiências com a interdisciplinaridade”. O Público e o Privado, 23:21-38.

Trajano Filho, Wilson \& Martins, Carlos. 2004. "Introdução”. In: W. Trajano Filho \& G. L. Ribeiro (orgs.), O campo da antropologia no Brasil. Rio de Janeiro: Contra Capa, p. 13-38, 269p.

Velho, Gilberto. 1973. A utopia urbana: um estudo de antropologia social. 6. ed. Rio de Janeiro: Zahar. 
- 1981. Individualismo e cultura: notas para uma antropologia da sociedade contemporânea. Rio de Janeiro: Zahar.

. 1994. Projeto e metamorfose: antropologia das sociedades complexas. Rio de Janeiro: Jorge Zahar.

Wolf, Eric. 1955. "Types of Latin American Peasantry: a Preliminary Discussion". American Anthropologist, 57:452-471. 